\title{
Growth in Telehealth Use in Bangladesh from 2019-202I - A Difference-in-Differences Approach
}

\author{
Saanjaana Rahman ${ }^{1,2 *}$, Sajid Amit ${ }^{1}$
}

\begin{abstract}
Purpose of the Project To examine the change in telehealth use growth during the COVID-19 pandemic with non-elderly patients in Bangladesh

Methods Using patients of age between 18-64 from residents in and outside Dhaka, this study analyzed telehealth visits, and all health care procedures from 2019-2021. The inflection point of interest was March 2020, the month when the COVID-19 pandemic was officially declared as a national emergency. Analyses were controlled for age, gender, and socioeconomic index. We used DiD approach to see the growth in telehealth use and then performed logistic regression to evaluate the association between any telehealth use and patient characteristics.

Results There were more than 3000 observations in the analysis, where more than $60 \%$ were female. The percentage of females did not decrease after the inflection point. The onset of the pandemic was associated with an increase in telehealth usage in Dhaka relative to outside Dhaka (DiD estimate 0.07; $95 \% \mathrm{Cl},-0.77-0.62)$. The mean telehealth visits in Dhaka after March 2020 was 33\% higher than outside Dhaka per person-year. The mean (SD) of Dhaka and outside Dhaka were 1.69 (7.03) and I.48 (7.62) respectively.

Interpretations Overall, telehealth use was associated with the youngest age group of 18-34, living in more urban areas and living in areas of higher socioeconomic status.

Conclusion In this study, we found a significant decrease to in-person services and a rise in telehealth visits.

Keywords: Telehealth, COVID-19 Pandemic, Patients, Health

DOI: https://doi.org//0.3329/jom.v23il.57936 Copyright: (C) 2022 Rahman S. This is an open access article published under the Creative Commons Attribution-NonCommercial-NoDerivatives 4.0 International License, which permits use, distribution and reproduction in any medium, provided the original work is properly cited, is not changed in any way and it is not used for commercial purposes.
\end{abstract}

Received: 10 November, 202I;

Accepted: 10 December, 2021

\section{Introduction}

Telehealth includes provider-to-patient and provider-toprovider encounters, allowing providers to deliver health care services remotely through the electronic channel. Although few people used telehealth services in the preCOVID-19 period, the pandemic has led to a significant rise in telehealth services, while some health systems reporting a whopping $4000 \%$ increase in appointment numbers during the peak of the pandemic. ${ }^{1}$

Telehealth is seen as a mode of delivery of health care services by healthcare professionals in cases where distance is a

1 Center for Enterprise and Society (CES), University of Liberal Arts Bangladesh (ULAB), Dhaka, Bangladesh

2 Population Health Sciences, Weill Cornell Medicine, Cornell University, New York, USA

*Corresponding author: Saanjaana Rahman, Center for Enterprise and Society (CES), University of Liberal Arts Bangladesh (ULAB), Dhaka, Bangladesh critical factor and uses information and communication technologies for the exchange of vital information among patients and providers. The benefits of using telehealth are many as remote care minimizes the use of resources in health centers, improves car access, and avoids transmission of COVID-19. Hence, many people during the pandemic considered telehealth as an attractive, effective, safe, and affordable option. ${ }^{30,33}$ We have seen recently that a rising percentage of individuals in the Bangladesh are turning to telehealth due in large part to changing telehealth policies during the pandemic.

\section{Literature Review}

Telehealth usage during the COVID-19 pandemic has become one of the vital tools for patients to seek medical assistance, where there are few studies regarding its utilization, but no studies have incorporated demographic and socioeconomic aspects of Bangladesh populations. 
Studies have analyzed the overall impact of telehealth by Teladoc, where only $7 \%$ of the patients had follow-up visits compared to patients who visited physicians' offices or emergency departments (ED) for similar conditions. ${ }^{3}$ Another study assessed how telemental health is deployed through semi-structured 60 minutes telephone interviews with providers and found $48 \%$ used a range of services. ${ }^{4}$ A study between March to April conducted a semi-structured interview with 20 outpatient psychiatrists in the top 5 States with COVID-19 cases and patients experienced satisfaction using telehealthcare services, but the inability to observe nonverbal cues, limited bandwidth, and incompatible devices were some issues for underserved patients ${ }^{[6]}$. Overall, $26.35 \%$ lacked some form of digital access, but the study design did not consider the effect of sex. ${ }^{31,32}$ In another study, the authors evaluated pediatric type 1 diabetes through telehealthcare during the COVID-19 pandemic by online survey and found $72 \%$ opted for future telehealthcare. ${ }^{8}$

Few papers examined the effectiveness of telemedicine for smoking cessation among rural patients through twenty primary care and safety net clinics, where $65 \%$ of the 566 participants earned below $200 \%$ of federal poverty level; and 560 participants over 3 month period respectively. The participants smoked almost a pack each day and were extremely motivated to quit. ${ }^{10,11}$

Systematic reviews showed that telehealth interventions produce positive outcomes when it's used for remote patient monitoring, especially for chronic conditions (e.g. cardiovascular and respiratory disease) and psychotherapy (e.g. behavioral health), with improvement in mortality rate, quality of life, and reduced hospital admissions, reduced patient time in the emergency department, reduced heart attack mortality in emergency services and improved access and clinical outcomes for outpatient consultations. ${ }^{12,13}$ Moreover, research in telehealth should be integrated with new models of payment and care to assess the continuum of care in organizations. There have been studies over four years of data from a nationally representative biannual consumer survey to telehealth use trends and the role policies play in its usage. ${ }^{14}$

The study can be expanded as the sample size will increase by adding low-income patients with limited internet access to know about their perceptions. In the pediatric type 1 diabetes study, only the patients with broadband and email access were able to do the study. ${ }^{17}$

Studies have overestimated the rates of telehealth use as it was conducted online and so excluded people with limited internet access, with the possibility of self-reported bias as the data was retrospective. Moreover, policies need to be made to incentivize providers and health systems to use telehealth even after the pandemic, such as by offering financial incentives to providers to adopt telehealth. It must be noted that even if telehealth service is widely available (i.e. during the COVID-19 pandemic), rural patients might not have complete information on how, when, and where to use it. Therefore, improving education in underserved communities can increase overall health outcomes. Federal, state, and local investments to improve telehealth infrastructure, which can provide enough access to rural populations and underserved communities.

The study have two research questions/objectives:

1. How did telehealth use change from 2019-2021?

2. What is the relationship between telehealth use and patient characteristics, including age, gender, and arealevel characteristics?

\section{Methods Study Sample and Assignment of Treatment}

We analyzed self-reported data collected from May 5 to July 30,2021 . For the first research question, our sample is from age 18 to 64 (non-elderly) and the study period is 2019 to 2021. Our inclusion criteria also included rural places (districts outside Dhaka) (control) and Dhaka residents (treatment). For the second research question, we used the same states and age group. All analyses were done in Stata 16.

\section{Study Outcomes}

The primary outcome of interest (dependent variables) was to see the change and DiD in the number of services used in terms of telehealth visits from 2019 to 2021 in control (residents outside Dhaka) and treatment (residents inside Dhaka) places. As we had utilization variables, we were able to capture the total number of inpatient and outpatient visits (for all the variables).

For secondary outcome, we wanted to see the usage of any telehealth visits in 2020 for both places, where we were able to see the association of any telehealth visits with patient characteristics such as age, gender and patient characteristics and all outcomes were adjusted for monthyear fixed effects. Apart from that, we also showed unadjusted trends (without adjusting for fixed effects) for all our outcomes, including telehealth visits, keeping March 2021 as the baseline threshold because that is when the pandemic was declared as a national emergency.

\section{Covariates}

We examined the covariates (independent variables) including gender, age, socioeconomic characteristics. Age was categorized into 4 groups with patients aged 18-34, 3544, 45-54, and 55-64 years old. 


\section{Statistical Analysis}

A difference-in-difference analysis is one of the most widely used techniques for analyzing the impact of policy change. Difference-in-differences (DiD) approaches are applied in situations when certain groups are exposed to treatment and others are not. The idea behind the DiD identification strategy is that the two groups might be observantly different, that is, the group-specific means might differ when the treatment is absent. If the difference is constant over time (absence of treatment), it can be differenced out by deducting group-specific means of the outcomes of interest. The remaining difference between the group-specific differences reflects the remaining causal effect of interest. The DiD approach is particularly well applied when estimating the causal effect of sharp changes in health policies (e.g. nonrandomized controlled trials), providing policymakers with vital information even in the absence of controlled or natural experiments. Hence, it has been used extensively to study the impacts of various health policy reforms in multiple countries. This method also helps in controlling for unobserved variables that bias estimates of causal effects, aided by longitudinal data. ${ }^{22} \mathrm{~A}$ general model for DiD is as follows:
$\mathrm{DD}=\left(\mathrm{Y}_{\mathrm{TR}, \mathrm{POST}}-\mathrm{Y}_{\mathrm{TR}, \mathrm{PRE}}\right)-\left(\mathrm{Y}_{\mathrm{C}, \mathrm{POST}}-\mathrm{Y}_{\mathrm{C}, \mathrm{PRE}}\right)$

where $\mathrm{TR}=$ treatment group

$\mathrm{POST}=$ after policy or reform

$\mathrm{C}=$ control group

$\mathrm{PRE}=$ before the policy or reform

$\mathrm{Y}=\beta \mathrm{o}+\beta 1 \mathrm{D}^{\mathrm{POST}}+\beta 2 \mathrm{D}^{\mathrm{TR}}+\beta 3 \mathrm{D}^{\mathrm{POST}} \mathrm{D}^{\mathrm{TR}}[+\beta 4 \mathrm{X}]+\varepsilon$

$\beta o$ is the constant and $\beta 4 \mathrm{X}$ is the interaction variables

Therefore, we used the difference-in-difference technique as the randomization on the individual level is not possible. We performed unadjusted trends (without any fixed effect) on all for outcomes to see how the COVID-19 pandemic changed intake on the number of services by patients in both places. The difference-in-difference regression framework quantified the changes in health care utilization in Dhaka relative to other districts before versus after March 2020, when the COVID-19 pandemic was declared a national emergency.

We first pulled data to descriptively show patterns of all outcomes (Table 1). After that, we used linear regression models for all outcomes, adjusting for month-year fixed effects.

For the second research question, we used logistic regression to evaluate the association between any telehealth use and patient characteristics.

Table 1 : Descriptive Statistics

\begin{tabular}{|c|c|c|c|c|}
\hline & $\begin{array}{l}\text { Residents in Dhaka } \\
\text { (Before 2020m3) }\end{array}$ & $\begin{array}{l}\text { Residents in Dhaka } \\
\text { (After 2020m3) }\end{array}$ & $\begin{array}{l}\text { Residents outside Dhak } \\
\text { (Before 2020m3) }\end{array}$ & $\begin{array}{l}\text { xa Residents outside } \\
\text { Dhaka (After 2020m3) }\end{array}$ \\
\hline Outcome & \multicolumn{4}{|c|}{$\mathrm{N}=3678$} \\
\hline \multicolumn{5}{|l|}{ Mean (SD) } \\
\hline Telehealth Visits & $0.15(2.31)$ & $1.69(7.03)$ & $0.12(1.75)$ & $1.48(7.62)$ \\
\hline \multicolumn{5}{|l|}{ Socioeconomic } \\
\hline \multicolumn{5}{|l|}{ Characteristics (\%) } \\
\hline \multicolumn{5}{|l|}{ Socioeconomic Index } \\
\hline $1^{\text {st }}$ Quartile (Lowest) & 20.10 & 19.88 & 38.20 & 37.64 \\
\hline $2^{\text {nd }}$ Quartile & 28.95 & 26.68 & 20.31 & 19.65 \\
\hline $3^{\text {rd }}$ Quartile & 41.14 & 43.57 & 19.98 & 21.12 \\
\hline $4^{\text {th }}$ Quartile (Highest) & 09.80 & 09.87 & 21.51 & 21.59 \\
\hline \multicolumn{5}{|l|}{ Patient Characteristics } \\
\hline Gender (F) (\%) & 61.59 & 61.45 & 60.81 & 60.44 \\
\hline \multicolumn{5}{|l|}{ Age Category (\%) } \\
\hline 1 (18-34 years) & 32.60 & 35.14 & 33.94 & 36.39 \\
\hline 2 (35-44 years) & 20.43 & 20.27 & 20.96 & 21.35 \\
\hline 3 (45-54 years) & 21.63 & 20.84 & 20.82 & 19.85 \\
\hline 4 (55-64 years) & 25.34 & 23.76 & 24.29 & 22.41 \\
\hline
\end{tabular}


In Table 1, both residents in and outside Dhaka had higher usage of telehealth visits, per person-year after March 2020, compared to before March 2020. Compared to residents outside Dhaka, the mean usage of those services was higher inside Dhaka in the post-period. Over $60 \%$ of the patients in the study were female and did not decrease substantially after March 2020. Among the age groups, the youngest age group of 18-34 years old part of the data ( $>30 \%$ ), followed by the oldest age group of 55-64 years old.

Table - 2 : Difference-in-differences Outcomes for the Relationship between Telehealth Use and Health Care Utilization

\begin{tabular}{lcccc}
\hline Outcome & Coef. & Robust SE & P-value & 95\% C.I. \\
\hline Telehealth Visits & 0.07 & 0.35 & 0.00 & $-0.77,0.62$ \\
In-Person Procedures & -0.06 & 0.01 & 0.00 & $-0.08,0.09$ \\
\hline
\end{tabular}

Telehealth visits per person-year had a coefficient of 0.07 with $\mathrm{p}<0.001$ but in-person procedures had a -0.06 coefficient. There was a significant differential increase in telehealth visits among residents ( $95 \% \mathrm{CI},-0.77-0.62)$. All standard errors were less than and the result was highly statistically significant at $\mathrm{p}<0.001$ (Table 2).

Table-3 : Logistic Regression Outcomes for the Association between Telehealth Use and Patient Characteristics

\begin{tabular}{lcccc}
\hline Outcome & Coef. & Robust SE & P-value & 95\% C.I. \\
\hline Age Category & & & & \\
2(35-44 years) & -0.07 & 0.01 & 0.00 & $-0.09,-0.04$ \\
3(45-54) & -0.08 & 0.02 & 0.00 & $-0.12,-0.05$ \\
4(55-64) & -0.09 & 0.02 & 0.00 & $-0.15,-0.05$ \\
Gender(Female) & 0.17 & 0.01 & 0.00 & $0.16,0.18$ \\
Socioeconomic Index & & & & \\
2nd Quartile & 0.18 & 0.04 & 0.00 & $-0.23,-0.01$ \\
3rd Quartile & -0.26 & 0.06 & 0.00 & $-0.24,0.06$ \\
4th Quartile (Highest) & -0.14 & 0.08 & 0.00 & $-0.50,-0.15$ \\
\hline
\end{tabular}

Compared to the youngest age group between 18-34, all other 3 age groups were negatively associated with telehealth usage as the coefficients were $-0.07,-0.08$, and -0.09 respectively. Females had a positive coefficient of 0.17 and $\mathrm{p}=0.00<0.001$.
The onset of the pandemic was associated with an increase in telehealth usage in the residents in Dhaka relative to the residents outside Dhaka as telehealth visits per person-year was 0.07 and it was highly statistically significant with $\mathrm{p}<0.001$. For the second research question, we saw that telehealth use was associated with younger age (18-34 years), living in more urban areas and higher socioeconomic status Table 3 .

\section{Conclusion and Discussion}

As we wanted to study growth in telehealth use from 20192020 and then we wanted to study the association between telehealth use and patient characteristics for both states. These findings are not only relevant to the patients using telehealth services who have lower access to care, but also to ministers, policymakers, and researchers in this field to make informed decisions on policies related to telehealth. The increases in telehealth use partially offset the decrease in in-person procedures-the use of which grew from near nonexistence to more than $40 \%$ at the pandemic's height, with older, and rural patients of lower socioeconomic status less likely to make the switch. ${ }^{23}$ The use of telehealth grew drastically during the onset of the pandemic explains how patients switched from in-person care and opted for virtual visits to reduce infection exposure. Patients with higher socioeconomic status were more likely to opt into telehealth (e.g. have higher literacy and technical knowledge in using telehealth platforms), while individuals living in areas with less education explain the disparities in terms of awareness, access, health literacy, and education. Although telehealth continues to be an important tool for care delivery, the substantial disparity in usage among the different age groups, socioeconomic status, and rural residence should be a call to action for providers and policymakers. The increased use of telehealth services among the younger age group explains the gap in technical and digital literacy which should be addressed.

However, those who are old and have limited English proficiency tend to lack technology literacy, which is a basic requirement for telehealth use, for which they are not able to use telehealth properly. Hence, even when policies and large funds are allocated for improving access, this sub-population within the elderly patients is failing to make use of that access. These sub-populations lack incentives in using telehealth and are associated with higher emergency use currently. ${ }^{25,29}$

Therefore, as a final take from the study, policies and expansion of telehealth including rural populations led to a positive outcome for many but left behind subpopulations within that could not benefit much from telehealth during the pandemic. Overcoming incentive issues and patient barriers within this subpopulations to using telehealth must 
include addressing multiple facets of the digital divide such as digital or technology literacy, linguistic facility, and eligibility criteria like a primary physician. These factors must be investigated to ensure meaningful engagement with telehealth for all, including these subpopulations. There are opportunities for developing multilevel policies to ensure equitable telehealth access and usage. Clinical practices, performance measures, and strategies must also be reformed to address gaps in telehealth for them during the COVID-19 emergency and beyond.

The vulnerable populations should be prioritized with developing proper strategies to mitigate the disparities in access to telehealth and maximize health care delivery and health care outcomes of all patients. A major strength in our study is that we chose residents in Dhaka versus residents outside Dhaka as that almost perfectly represent Bangladesh. Additionally, our approach to use $\mathrm{DiD}$ is a useful technique as randomization on the individual level was not possible and this method helped understand the trend of telehealth use and other outcomes of interest before and after the onset of a pandemic. One of the limitations includes the study did not include other socioeconomic characteristics such as income, education, and current profession, which if included might have provided us with more insights into health inequities and disparities among the patients. Future work should follow up on that.

Conflict of Interest: The authors declare no conflict on interest.

Acknowledgments: Nothing to be reported

Funding/Supports: Nothing to be reported

\section{References}

1. Telehealth seems here to stay - so how can it be improved? Healthcareitnews.com. 2020 [cited 2021 Dec 10]. Available from: https://www.healthcareitnews.com/news/telehealthseems-here-stay-so-how-can-it-be-improved

2. Monaghesh E, Hajizadeh A. The role of telehealth during COVID-19 outbreak: A systematic review based on current evidence. BMC Public Health. 2020;20(1).

3. Brown JD, Hales S, Evans TE, Turner T, Sword DO, O'Neil $\mathrm{PM}$, et al. Description, utilisation and results from a telehealth primary care weight management intervention for adults with obesity in South Carolina. J Telemed Telecare [Internet]. 2020;26(1-2):28-35. Available from: http://dx.doi.org/ $10.1177 / 1357633$ X18789562

4. Choi NG, Wilson NL, Sirrianni L, Marinucci ML, Hegel MT. Acceptance of home-based telehealth problem-solving therapy for depressed, low-income homebound older adults: qualitative interviews with the participants and aging-service case managers. Gerontologist [Internet]. 2014;54(4):70413. Available from: http://dx.doi.org/10.1093/geront/gnt083

5. Choi H, Kim J. Effectiveness of telemedicine: videoconferencing for low-income elderly with hypertension. Telemed J E Health [Internet]. 2014;20(12):1156-64. Available from: http://dx.doi.org/10.1089/tmj.2014.0031

6 Uscher-Pines L, Mehrotra A. Analysis of Teladoc use seems to indicate expanded access to care for patients without prior connection to a provider. Health Aff (Millwood) [Internet]. 2014;33(2):258-64. Available from: http:// dx.doi.org/10.1377/hlthaff.2013.0989

7 Uscher-Pines L, Mulcahy A, Cowling D, Hunter G, Burns $\mathrm{R}$, Mehrotra A. Access and quality of care in direct-toconsumer telemedicine. Telemed J E Health [Internet]. 2016;22(4):282-7. Available from: http://dx.doi.org/10.1089/ tmj.2015.0079

8. Fung A, Irvine M, Ayub A, Ziabakhsh S, Amed S, Hursh BE. Evaluation of telephone and virtual visits for routine pediatric diabetes care during the COVID-19 pandemic. J Clin Transl Endocrinol [Internet]. 2020;22(100238):100238. Available from: http://dx.doi.org/10.1016/j.jcte.2020.100238

9. Talbot JA, Burgess AR, Thayer D, Parenteau L, Paluso N, Coburn AF. Patterns of telehealth use among rural Medicaid beneficiaries: Rural telehealth use in medicaid. J Rural Health [Internet]. 2019;35(3):298-307. Available from: http:// dx.doi.org/10.1111/jrh.12324

10 Liebmann EP, Preacher KJ, Richter KP, Cupertino AP, Catley D. Identifying pathways to quitting smoking via telemedicine-delivered care. Health Psychol [Internet]. 2019;38(7):638-47. Available from: http://dx.doi.org/ $10.1037 /$ hea 0000740

11 Mussulman L, Ellerbeck EF, Cupertino AP, Preacher KJ, Spaulding R, Catley D, et al. Design and participant characteristics of a randomized-controlled trial of telemedicine for smoking cessation among rural smokers. Contemp Clin Trials [Internet]. 2014;38(2):173-81. Available from: http:/ /dx.doi.org/10.1016/j.cct.2014.04.008

12 Posey R. AHRQ - telehealth - mapping the evidence for patient outcomes from systematic reviews $\cdot$ mTelehealth [Internet]. Mtelehealth.com. 2016 [cited 2021 Dec 10]. Available from: https://mtelehealth.com/ahrq-telehealthmapping-the-evidence-for-patient-outcomes-fromsystematic-reviews/

13 Expanding telehealth and telementoring during COVID-19: AHRQ's expertise helps identify next steps [Internet]. Ahrq.gov. [cited 2021 Dec 10]. Available from: https:// www.ahrq.gov/news/blog/ahrqviews/expandingtelehealth.html

14 Park J, Erikson C, Han X, Iyer P. Are state telehealth policies associated with the use of telehealth services among 
underserved populations? Health Aff (Millwood) [Internet]. 2018;37(12):2060-8. Available from: http://dx.doi.org/ $10.1377 /$ hlthaff.2018.05101

15 Www.va.gov. [cited 2021 Dec 10]. Available from: https:// www.va.gov/healthpolicyplanning/soe2017/ va_enrollees_report_data_findings_report2.pdf

16 Volk J, Palanker D, O'Brien M, Goe CL. States' actions to expand telemedicine access during COVID-19 and future policy considerations [Internet]. Commonwealth Fund; 2021 [cited 2021 Dec 10]. Available from: https:// www.commonwealthfund.org/publications/issue-briefs/ 2021/jun/states-actions-expand-telemedicine-access-covid19

17 Chiang JL, Maahs DM, Garvey KC, Hood KK, Laffel LM, Weinzimer SA, et al. Type 1 diabetes in children and adolescents: A position statement by the American diabetes association. Diabetes Care [Internet]. 2018;41(9):2026-44. Available from: http://dx.doi.org/10.2337/dci18-0023

18 The Promise of Telehealth. 2021.

19 Frameworks to address social determinants of health - RHIhub toolkit [Internet]. Ruralhealthinfo.org. [cited 2021 Dec 10]. Available from: https://www.ruralhealthinfo.org/toolkits/ sdoh/1/frameworks

20 Homepage - COVID-19 research database [Internet]. Covid19researchdatabase.org. 2020 [cited 2021 Dec 10]. Available from: https://covid19researchdatabase.org

21 Office Ally - Home [Internet]. Officeally.com. [cited 2021 Dec 10]. Available from: https://cms.officeally.com

22 Difference-in-Difference Estimation [Internet]. Columbia.edu. [cited 2021 Dec 10]. Available from: https:// www.publichealth.columbia.edu/research/population-healthmethods/difference-difference-estimation

23 Rezaian MM, Brent LH, Roshani S, Ziaee M, Sobhani F, Dorbeigi A, et al. Rheumatology care using telemedicine. Telemed J E Health [Internet]. 2020;26(3):335-40. Available from: http://dx.doi.org/10.1089/tmj.2018.0256

24 Health.ny.gov. [cited 2021 Dec 10]. Available from: https:// health.ny.gov/health_care/medicaid/covid19/docs/faqs.pdf

25 Rodriguez JA, Saadi A, Schwamm LH, Bates DW, Samal L. Disparities in telehealth use among California patients with limited English proficiency. Health Aff(Millwood) [Internet]. 2021;40(3):487-95. Available from: http://dx.doi.org/ $10.1377 /$ hlthaff.2020.00823
26 The American Rescue Plan Act and healthcare providers - A first look [Internet]. Morganlewis.com. [cited 2021 Dec 10]. Available from: https://www.morganlewis.com/pubs/2021/ 03/the-american-rescue-plan-act-and-healthcare-providers-afirst-look-first 100

27 Lin M-H, Yuan W-L, Huang T-C, Zhang H-F, Mai J-T, Wang J-F. Clinical effectiveness of telemedicine for chronic heart failure: a systematic review and meta-analysis. J Investig Med [Internet]. 2017;65(5):899-911. Available from: http:/ /dx.doi.org/10.1136/jim-2016-000199

28 Roberts ET, Mehrotra A. Assessment of disparities in digital access among medicare beneficiaries and implication for telemedicine. JAMA: Journal of American Medical Association Intern Med [Internet]. 2020;180(10):1386-89. Available from: http://dx.doi.org/10.

29 So CF, Chung JW. Telehealth for diabetes self-management in primary healthcare: A systematic review and meta-analysis. J Telemed Telecare [Internet]. 2018;24(5):356-64. Available from: http://dx.doi.org/10.1177/1357633X17700552

30 Uscher-Pines L, Sousa J, Raja P, Mehrotra A, Barnett ML, Huskamp HA. Suddenly becoming a "virtual doctor": Experiences of psychiatrists transitioning to telemedicine during the COVID-19 pandemic. Psychiatr Serv [Internet]. 2020;71(11):1143-50. Available from: http://dx.doi.org/ 10.1176/appi.ps.202000250

31 Uscher-Pines L, Raja P, Qureshi N, Huskamp HA, Busch $\mathrm{AB}$, Mehrotra A. Use of Tele-mental health in conjunction with in-person care: A qualitative exploration of implementation models. Psychiatr Serv [Internet]. 2020;71(5):419-26. Available from: http://dx.doi.org/ 10.1176/appi.ps.201900386

32 Telehealth for acute and chronic care consultations [Internet]. Ahrq.gov. [cited 2021 Dec 10]. Available from: https:// effectivehealthcare.ahrq.gov/products/telehealth-acutechronic/research

33 Telehealth seems here to stay - so how can it be improved? [Internet]. Healthcareitnews.com. 2020 [cited 2021 Dec 10]. Available from: https://www.healthcareitnews.com/news/ telehealth-seems-here-stay-so-how-can-it-be-improved

34 Iqbal MH. Telemedicine: An innovative twist to primary health care in rural Bangladesh. J Prim Care Community Health [Internet]. 2020;11:2150132720950519. Available from: http://dx.doi.org/10.1177/2150132720950519 